\title{
O Programa Bolsa Família a partir do território: o trabalho social com as famílias beneficiárias
}

\author{
BolsaFamilia Program analyzed from a territory view: The social work with beneficiary \\ families.
}

Tatiana de Oliveira Stechi*

\begin{abstract}
Resumo:
O presente artigo tem como objetivo apresentar algumas reflexões sobre o trabalho social com famílias beneficiárias do Programa Bolsa Família (PBF), a partir do território, eixo estruturante da Política Nacional de Assistência Social (PNAS). Com base na experiência prática e na atuação profissional, se faz necessária uma compreensão do trabalho social realizado com as famílias beneficiárias desse programa, enquanto possibilidade de intervenção qualificada em relação a suas necessidades e demandas, tendo como parâmetro o incremento das políticas sociais de transferência de renda como enfrentamento à pobreza. Neste sentido, o estudo contextualiza o programa federal de transferência de renda, seus objetivos, critérios e público beneficiário, e o situa no trabalho desenvolvido pelos Centros de Referência de Assistência Social (CRAS), com base nas orientações dadas pela PNAS. A partir das orientações dadas pela legislação vigente e por teorias que direcionam a prática e a atuação do assistente social com essas famílias, o trabalho em questão deve ser desenvolvido em rede, articulado com as demais políticas, no âmbito do território, e as intervenções profissionais devem considerar o local em que as famílias vivem para $o$ atendimento de suas demandas.
\end{abstract}

Palavras-chave: Programa bolsa família. Território. Família. Centro de referência da assistência social. Proteção social básica.

\begin{abstract}
:
This article has the objective to present some of the viewpoints around the social work done with families participating in the Bolsa Familia Program (BFP) from its territory view, a structural axis of the Social Assistance National Politics (SANP). Considering practical experience as well as professional knowledge, a qualified intervention on the necessities and demands of the beneficiaries are seen as necessary to understand the social work that has been done with these families. This intervention should include the increase of social politics of income transference and the battle of poverty as parameters. The federal income transference program is in this context, as well as its objectives and criteria. Subsequently, it points out the work that has been developed by the Social Assistance Centers of Reference (SACR) and the orientations given by
\end{abstract}

\footnotetext{
*Assistente Social, especialista em Saúde Mental, mestranda do curso de pós-graduação em Serviço Social e Políticas Sociais da UEL- tatistechi@yahoo.com.br
} 
SANP focusing on the beneficiary families as the public priority. Legislation and theories should direct orientations to do social work with theses families since it is necessary to develop an articulated work, taking territory politics in consideration as well as families needs and professional intervention.

Keywords: Bolsa familia program. Territory. Family. social assistance centers of reference. Basic social protection.

\section{Introdução}

A constituição de 1988 foi um marco, pois introduziu a Assistência Social no campo da Seguridade Social, enquanto política que compõe o sistema de proteção social no Brasil, em conjunto com a previdência social e a saúde. Assim, a assistência social passou a ser reconhecida enquanto política pública de caráter não contributivo, como dever do Estado, direcionada a quem dela necessitar.

A partir da década de 1990, foram introduzidas, no Brasil, perspectivas neoliberais por organismos internacionais e multilaterais (Banco Mundial e Fundo Monetário Internacional - FMI), o que ocasionou expressivas mudanças no contexto nacional e, consequentemente, no Serviço Social brasileiro. Em meio às expressões da questão social no mundo contemporâneo, pôde-se verificar um aumento expressivo da desigualdade, cujos efeitos na vida da população atendida pelo Serviço Social são extremamente significativos.

Vale ressaltar que a pobreza, no país, e, portanto, a desigualdade social, é histórica, estrutural e multidimensional. Dessa forma, a história evidencia que a pobreza é, também, fruto de um processo de colonização que tinha por objetivo a exploração das riquezas minerais e vegetais do país que estava submetido ao capital externo, o que, de fato, proporcionou o enriquecimento somente dos que estavam no poder. Neste aspecto, a pobreza e a desigualdade social carregam dimensões culturais, sociais, econômicas e históricas, fato que coloca em questão inúmeros desafios para atuação do assistente social.

O Serviço Social, nesse contexto, passou por vários momentos de questionamento em relação à sua atuação frente às expressões da questão social que emergiam, o que desencadeou inúmeros debates no âmbito da categoria profissional. A assistência social, por sua vez, só foi reconhecida, enquanto política pública, no Brasil, em 1988, quando rompeu com a perspectiva assistencialista de sua gênese. 
Nesse contexto, no ano de 1993, foi sancionada a Lei Orgânica da Assistência Social (LOAS), regulamentada enquanto política que viabiliza a garantia de direitos e promove a cidadania. Posteriormente, com a implantação do Sistema Único de Assistência Social (SUAS) e com o direcionamento para o atendimento descentralizado através dos CRAS, há a introdução de novas normativas que regulam o trabalho do assistente social com famílias a partir do território.

No ano de 2003, foi criado, pelo governo Lula, o Bolsa Família, a partir da unificação de programas remanescentes como: Cartão Alimentação, Vale Gás e Bolsa Escola, que foram configurados em um único benefício social de transferência de renda. Vale considerar o número significativo de famílias, hoje, beneficiárias do programa e, desse modo, usuárias da política de assistência social, por meio do CRAS, enquanto público prioritário de intervenção, conforme orientação dada pelo Ministério de Desenvolvimento Social e Combate à Fome (MDS).

O Serviço de Proteção e Atendimento Integral à Família (PAIF) compõe um dos serviços de proteção social básicos ofertados pelos CRASs, cujo objetivo é fortalecer a função protetiva das famílias, visando a: prevenção de ruptura de vínculos; promoção do acesso e usufruto de direitos; e o desenvolvimento de trabalho social com famílias beneficiárias do Programa Bolsa Família (PBF). Esse trabalho é fundamental na medida que se considera a proteção social para além da transferência de renda.

Parte-se, assim, da compreensão de que o trabalho social pode viabilizar ações do poder público dirigidas a famílias beneficiárias do programa em questão, com a finalidade de disseminar informações, de modo a promover a garantia do acesso aos direitos, proporcionando, desse modo, a superação das vulnerabilidades sociais para além da renda.

Num contexto em que o Estado adota perspectivas neoliberais que priorizam o mercado e o capital em detrimento do social, há que se considerar que se instaurou, no Brasil, um processo de exclusão social, desse modo, é necessário desenvolver um olhar crítico para a realidade circundante e, ao mesmo tempo, ser realista e propositivo na elaboração de políticas e programas sociais, considerando a necessidade efetiva das famílias que são a demanda do cotidiano de trabalho no CRAS. Para isso, é fundamental que o trabalho do assistente social seja fundado em um conhecimento continuado, 
baseado em uma ação metodológica e em uma avaliação permanente, que garanta melhores resultados nas ações interventivas com as famílias.

Nesse contexto, este estudo teve como finalidade tecer reflexões sobre o trabalho social com famílias beneficiárias do PBF a partir do território em que vivem, com base em uma pesquisa bibliográfica sobre a temática em questão e em uma análise documental.

O presente artigo está organizado em dois momentos: o primeiro consiste em uma apresentação do PBF, ou seja, seus objetivos, critérios e formas de acesso; o segundo compreende reflexões sobre as orientações para o trabalho social com famílias, executado pelo PAIF, nos CRAS, com base nos dois eixos estruturantes do SUAS.

\section{O programa bolsa família}

O Programa Bolsa Família (PBF) é um programa de transferência direta de renda, direcionado a famílias com renda per capita de até $\mathrm{R} \$ 140,00$, que se encontram em situação de pobreza ou extrema pobreza. De acordo com MDS, famílias em situação de extrema pobreza são as com renda per capita entre $\mathrm{R} \$ 00,00$ a $\mathrm{R} \$ 70,00$; já as famílias em situação de pobreza são as que possuem renda per capita entre $\mathrm{R} \$ 70,01$ a $\mathrm{R} \$ 140$. $\mathrm{O}$ programa compreende três eixos principais, focados na transferência de renda, nas condicionalidades e em ações e programas complementares (BRASIL, 2006a).

Conforme Silva (2007), o Bolsa Família foi criado por meio da Medida Provisória nำ132, de 20 de outubro de 2003, posteriormente, transformada em lei, a Lei № 10.836, sendo que o Programa Fome Zero foi por ele incorporado. O Decreto no 5.209, de 17 de setembro de 2004, esclarece que a finalidade do programa é unificar os procedimentos de administração e execução de ações de transferência de renda, em cadastramento único do governo federal (BRASIL, 2004).

Weissheimer (2006) apresenta o Bolsa Família como um programa federal de transferência direta de renda, destinado a famílias em situação de pobreza, fundamentado em dois objetivos básicos: combater a miséria e a exclusão social e promover a emancipação das famílias mais pobres.

O Guia do Gestor (BRASIL, 2006b) define o Bolsa Família como um programa de transferência direta de renda que embute condições a serem cumpridas pelas famílias beneficiadas. Essas contrapartidas estão articuladas ao ingresso dos beneficiários à rede de 
serviços públicos, como Educação, Saúde e Assistência Social. Dessa forma, para se alcançar esse objetivo, é necessária a articulação de três dimensões essenciais:

\begin{abstract}
A primeira delas refere-se ao alívio imediato da pobreza, por meio da transferência direita de renda à família. A segunda dimensão diz respeito ao reforço que o Bolsa Família oferece ao exercício de direitos sociais básicos nas áreas de Saúde e Educação, que contribui para que as famílias consigam romper o ciclo da pobreza entre gerações. Essa dimensão concretiza-se nas condicionalidades ou compromissos que as famílias devem cumprir para participarem do Programa. [...] A terceira dimensão do Bolsa Família, os chamados programas complementares.São programas de geração de trabalho e renda, de alfabetização de adultos, de fornecimento de registro civil e demais documentos, entre outros programas que podem ser ofertados pelas três esferas de governo e sociedade civil (BRASIL, 2006b, p. 7-8).
\end{abstract}

De acordo com Suplicy (2004), as famílias beneficiárias do PBF devem, como contrapartida, comprovar: que suas crianças de até seis anos estão sendo vacinadas de acordo com o calendário do Ministério da Saúde; que o desenvolvimento nutricional das mesmas está sendo acompanhado pela Unidade Básica de Saúde (UBS); que as crianças de seis a quinze anos frequentam, regularmente, a escola; e que os adultos participam de algum curso de alfabetização ou de capacitação para se prepararem para a inserção no mercado de trabalho.

Entretanto, vale ressaltar que o programa passou por implementações no decorrer desses dez anos de existência, pois houve mudanças nos critérios para o recebimento como nos valores dos benefícios.

Dessa forma, os valores dos benefícios recebidos pelas famílias variam de acordo com a renda declarada, neste sentido, iniciam-se, basicamente, com um valor de $\mathrm{R} \$ 32,00$ por criança e de $\mathrm{R} \$ 38,00$ por adolescentes entre 15 e 17 anos. Com a introdução da ação "Brasil Carinhoso", no governo Dilma, mais, especificamente, no ano de 2012, com objetivo de superar a extrema pobreza no Brasil, os valores dos benefícios tiveram um aumento no chamado Bolsa Superação da Pobreza (BSP), cujo valor inicial é de R\$32,00, mas pode chegar ao valor necessário para a superação da renda per capita de $\mathrm{R} \$ 70,00$, dependendo, para tanto, do número de filhos (crianças e adolescentes) e da renda familiar.

Nesse contexto, uma família com cinco pessoas, sendo a mãe e 04 filhos com idades de até 15 anos, com renda familiar total de $\mathrm{R} \$ 100,00$ e renda per capita de $\mathrm{R} \$ 20,00$, receberá $\mathrm{R} \$ 70,00$ de benefício básico mais $\mathrm{R} \$ 32,00$ por filho, totalizando um benefício de $\mathrm{R} \$ 198,00$. Com o BSP, passará a receber $\mathrm{R} \$ 250,00$ por mês. 
De acordo com o MDS (BRASIL, 2006a), a transferência de renda tem como objetivo promover o alívio imediato na pobreza. As condicionalidades buscam reforçar o acesso a direitos sociais básicos nas áreas de educação, saúde e assistência social. Já as ações e os programas complementares objetivam o desenvolvimento das famílias, de modo que os beneficiários consigam superar a situação de vulnerabilidade.

A seleção das famílias beneficiárias se dá a partir de informações inseridas pelo município no Cadastro Único para Programas Sociais do Governo Federal (Cadúnico) . O Cadúnico é um instrumento de coleta de dados, cujo objetivo é identificar todas as famílias em situação de pobreza existentes no país.

O trabalho social realizado com as famílias beneficiárias do PBF fundamenta-se em dois eixos estruturantes do SUAS: o território e a matricialidade sociofamiliar.

\section{Trabalho social com famílias e território}

$\mathrm{Na}$ atual conjuntura, pós Constituição de 1988, a assistência social passou por mudanças significativas, com o objetivo de romper com a tradição de assistencialismo e configurar-se enquanto política pública. Neste sentido, incorporou-se o investimento em ações preventivas e de melhoria da qualidade de vida, desenvolvidas de forma planejada e contínua, não mais pontuais e emergenciais.

Teixeira (2010b) aponta que a política de assistência social tem buscado superar a visão de pobreza baseada apenas na ausência ou precariedade de renda e/ou em atendimentos a segmentos isolados e parcializados, dirigindo a atenção às famílias, bem como, a suas necessidades. Neste sentido, aponta que há expectativas em relação ao trabalho social com famílias, por meio de práticas socioeducativas alternativas, dirigidas ao protagonismo das mesmas.

Para o desenvolvimento de um trabalho social que vá ao encontro das reais necessidades das famílias beneficiárias do PBF e vislumbre a proteção social para além da transferência de renda, de modo a oportunizar o acesso às políticas públicas e aos direitos sociais, é necessário conhecer a realidade do território em que vivem tais famílias, bem como, suas vulnerabilidades, potencialidades, fragilidades, riscos sociais, cultura, histórias de vida e relações sociais, indicadores essenciais para o direcionamento da atuação profissional. 
De acordo com Lougon, Cruz e Santos (2007), na história da sociedade brasileira, a questão territorial não teve relevância no momento da formulação de políticas sociais, pois não eram consideradas as desigualdades e as diferenças existentes entre as cidades e o interior destas. Foi somente após a aprovação da Constituição Federal de 1988 que uma nova diretriz passou a fundamentar o planejamento e o desenvolvimento da política de Assistência Social no Brasil: a descentralização político-administrativa.

A partir de então, os municípios passaram a ser pensados como locais onde as políticas sociais, especificamente, as políticas de assistência social são implementadas, considerando-se as necessidades e especificidades de cada território, ou seja, de cada localidade.

A política de Assistência Social, na atual conjuntura, estabeleceu um nível de hierarquização por ordem de complexidade, ou seja, proteção básica e proteção especial, sendo esta última dividida em alta e média complexidade. Nesse sentido, para orientar a padronização dos serviços a serem prestados em cada modalidade protetiva, foi criada uma tipificação nacional de serviços socioassistenciais (aprovada pela Resolução CNAS 109, de $11 / 11 / 2009$, e publicada no DOU, em $25 / 11 / 2009$ ), que apresenta os objetivos desses serviços por nível de complexidade do SUAS e sua aquisição por parte dos usuários (BRASIL, 2009b).

O enfoque, neste estudo, é a proteção social básica e o trabalho realizado pelos técnicos no âmbito do CRAS, por meio da execução do PAIF. Dessa forma, a abordagem focaliza a proteção social básica, que deve atuar como prevenção à violação de direitos, objetivando o fortalecimento de indivíduos e famílias que se encontram em situação de vulnerabilidade social, ou seja, que correm o risco de terem seus direitos violados, caso não sejam amparados em suas fragilidades.

Vale ressaltar que, na PNAS (BRASIL, 2005b) e na NOB-SUAS (2005a), foram introduzidos novos conceitos em relação à concepção da política de assistência social, bem como, novos direcionamentos quanto ao processo de gestão e articulação da rede de proteção. Nesse campo de análise, importa destacar a visão socioterritorial que enfatiza o novo modo de se compreender e de se atuar na realidade, ou seja:

Uma visão social inovadora, pautada na dimensão ética de incluir "os invisíveis" enquanto integrantes de uma situação social coletiva; uma visão que exige o 
reconhecimento para além das demandas setoriais e segmentadas, afirmando que o chão onde se encontram e se movimentam setores e segmentos fazem a diferença no manejo da própria política; uma visão social que exige relacionar as pessoas e seus territórios, identificando no cotidiano do "território vivido", os riscos e vulnerabilidades, mas também as potencialidades e os recursos disponíveis; uma visão que se pauta na perspectiva socioterritorial, cujas intervenções se dão nas capilaridades dos territórios, a partir do reconhecimento da dinâmica que se processa no cotidiano das populações (BRASIL, 2005a, p. 15).

Andrade (2012) em relação a esse novo conceito, pontua que tal visão requer a articulação de novos referenciais teórico-metodológicos, assim como, de novas práticas sociais. Assim, é necessária uma compreensão aprofundada da realidade socioterritorial, que é altamente desigual, dinâmica e complexa, para se buscar uma aproximação com o cotidiano da população usuária, pois é no dia-a-dia que as condições e o modo de vida da população se expressam concretamente. Para tanto, é preciso analisar as formas de organização familiar no território, ou seja, considerar aspectos geracionais e de gênero, valores construídos e relações comunitárias, para garantir o bem estar das famílias. Neste sentido, é necessário reconhecer as dinâmicas locais e a repercussão destas na realidade cultural, econômica e social, no território e na vida das pessoas.

A PNAS (BRASIL, 2005a) considera a heterogeneidade e a desigualdade socioterritorial presentes no Brasil. Assim, "ao invés de metas setoriais a partir de demandas ou necessidades genéricas," busca "identificar os problemas concretos, as potencialidades e as soluções, a partir de recortes territoriais" (BRASIL, 2005a, p. 44). Neste sentido, trabalhar com a questão do território implica considerar não só suas características demográficas, mas também suas especificidades geográficas e sociais.

Para Lougon, Cruz e Santos (2007), a territorialização deve absorver as especificidades locais presentes no interior de cada território, o que possibilita o desenvolvimento de ações voltadas, efetivamente, para as demandas da população dos diferentes espaços.

A concepção de território adotada pela PNAS vai além da delimitação espacial. Segundo o documento, o território não é somente uma porção específica de terra, mas uma localidade marcada pelas pessoas que ali vivem. É nos espaços coletivos que se expressam: a solidariedade; a extensão das relações familiares, para além da consanguinidade; o fortalecimento da cumplicidade e da vizinhança; e o desenvolvimento do sentimento de pertença e identidade. O conceito de território, então, abrange as 
relações de reconhecimento, afetividade e identidade entre os indivíduos que compartilham a vida em uma determinada localidade. Neste sentido, Santos (2000, p. 22) assinala que "o território em si não é um conceito. Ele só se torna um conceito utilizável para a análise social quando o consideramos a partir de seu uso, a partir do momento em que o pensamos juntamente com aqueles atores que dele se utilizam."

Segundo Koga (2003), é possível compreender o território a partir da dinâmica das pessoas que participam de sua constituição, sendo assim:

\begin{abstract}
A apropriação do território diz respeito ao aspecto interventivo realizado pelos homens, criando e recriando significados em torno dessa apropriação cotidiana. Nesse sentido, utiliza-se também o termo territorialidade, como uma maneira singular de se apropriar, fazer uso da terra, do território (KOGA, 2003, p. 38).
\end{abstract}

A autora ressalta, ainda, o fato de que "a territorialidade se faz pelos significados e ressignificações que os sujeitos vão construindo em torno de suas experiências de vida em dado território." (KOGA, 2003, p. 38).

Com base no conceito de território, aqui apresentado, na diretriz da descentralização político-administrativa da assistência social e, consequentemente, na constituição do CRAS em áreas de vulnerabilidade social, a PNAS (BRASIL, 2005a) define que os programas e os projetos de proteção social básica a serem desenvolvidos nos CRASs devem priorizar o acolhimento, a convivência e a socialização de famílias e indivíduos. O CRAS, equipamento público responsável pelo oferecimento da proteção socioassitencial básica, constitui:

[...] uma unidade da rede socioassistencial de proteção social básica que se diferencia das demais, pois, além da oferta de serviços e ações, possui as funções exclusivas de oferta pública do trabalho social com famílias do PAIF e de gestão territorial da rede socioassistencial de proteção social básica. Esta última função demanda do CRAS um adequado conhecimento do território, a organização e articulação das unidades da rede socioassistencial a ele referenciadas e o gerenciamento do acolhimento, inserção, do encaminhamento e acompanhamento dos usuários no SUAS (BRASIL, 2009a).

No processo de efetivação da proteção básica de assistência social, o CRAS exerce papel central, pois foi concebido como "porta de entrada" para o SUAS. A PNAS (BRASIL, 2005a) ressalta a importância da diretriz da territorialização, ao considerar a alta densidade populacional do país, seu alto grau de heterogeneidade e sua grande desigualdade territorial. 
O CRAS, enquanto dispositivo operacionalizador e gestor da proteção social básica, em seu território de abrangência, assume os dois eixos estruturantes do modelo de gestão do SUAS: a territorialização e a matricialidadesociofamiliar. A matricialidadesociofamilar, enquanto eixo estruturante da gestão, pressupõe que

[...] a política de assistência social reconhece que somente é possível tecer uma rede de proteção social ao se compreender os determinantes familiares de uma situação de vulnerabilidade social e acolher mais de um membro dessa família na busca da superação dessa situação (BRASIL, 2009a, p. 12).

O mesmo documento apresenta, da seguinte forma, a relevância da territorialização como eixo estruturante da gestão do CRAS:

O CRAS materializa a presença do Estado no território, possibilitando a democratização do acesso aos direitos socioassistenciais e contribuindo para o fortalecimento da cidadania. Ao eleger a territorialização como eixo estruturante do SUAS, reconhece-se que a mobilização das forças no território e a integração de políticas públicas podem potencializar iniciativas e induzir processos de desenvolvimento social. A integração de políticas, por sua vez, é potencializada pela clareza de objetivos e pela definição de diretrizes governamentais (BRASIL, 2009a, p. 13-14).

O CRAS, enquanto dispositivo articulador da rede de proteção social e viabilizador do acesso aos direitos de cidadania, deve manter "ativos os mecanismos de vigilância da exclusão social por meio da produção, sistematização e divulgação de indicadores sociais da área de sua abrangência." (BRASIL, 2008, p. 43).

O CRAS também atua na execução do PAIF, cujos usuários são famílias residentes em seu território de abrangência, que vivem em situação de vulnerabilidade social decorrente de: pobreza; precário ou nulo acesso a serviços públicos; fragilização de vínculos de pertencimento e sociabilidade; e/ou qualquer outra situação de vulnerabilidade e risco social.

Nesse sentido, enquanto público prioritário, o CRAS atende as seguintes situações consideradas de maior vulnerabilidade social: famílias beneficiárias do Programa Bolsa Família em descumprimento de condicionalidades; famílias do Programa de Erradicação do Trabalho Infantil - PETI, em descumprimento de condicionalidades; famílias com pessoas com deficiência entre 0 e 18 anos, beneficiárias do BPC; famílias beneficiárias do Programa Bolsa Família e/ou em situação de risco com jovens entre 15 e17 anos. 
O CRAS também acaba sendo responsável por organizar a vigilância social em seu território de abrangência. Portanto, deve viabilizar a produção e a sistematização de informações que possibilitem a construção de indicadores territorializados no que diz respeito a situações de vulnerabilidade e risco que incidem sobre famílias nos diferentes ciclos de vida. Esses indicadores potencializam e organizam a oferta de serviços socioassistenciais e a rede de proteção social básica do SUAS no território, conforme a necessidade.

Como o CRAS atua com famílias em situação de vulnerabilidade social, tem como objetivo, conforme as orientações da tipificação dos serviços:

\begin{abstract}
Fortalecer a função protetiva da família, contribuindo na melhoria da sua qualidade de vida; Prevenir a ruptura dos vínculos familiares e comunitários, possibilitando a superação de situações de fragilidade social vivenciadas; Promover aquisições sociais e materiais às famílias, potencializando o protagonismo e a autonomia das famílias e comunidades; Promover acessos a benefícios, programas de transferência de renda e serviços socioassistenciais, contribuindo para a inserção das famílias na rede de proteção social de assistência social; Promover acesso aos demais serviços setoriais, contribuindo para o usufruto de direitos; Apoiar famílias que possuem, dentre seus membros, indivíduos que necessitam de cuidados, por meio da promoção de espaços coletivos de escuta e troca de vivências familiares (BRASIL, 2009a, p. 7).
\end{abstract}

Nesse sentido, é necessário que os trabalhadores do CRAS estejam atentos às possibilidades existentes no território e tenham conhecimento das histórias de vida e das relações sociais estabelecidas, para que possam planejar os encaminhamentos e as articulações da rede de serviços, de modo que os procedimentos sejam, de fato, efetivos e venham ao encontro das demandas e necessidades da população.

Nesse sentido, se faz necessário conhecer o que deve ser considerado no processo de acompanhamento de famílias beneficiárias do $\mathrm{PBF}$, enquanto público prioritário do PAIF, no âmbito do território de abrangência do CRAS, pois este envolve vários fatores, como a construção de identidade e pertencimento no território de referência.

Entre as ações que devem ser desenvolvidas no âmbito do PAIF, estão: acolhida, oficinas com as famílias, ações comunitárias, ações particularizadas e encaminhamentos. De acordo com as Orientações Técnicas sobre o PAIF, essas ações devem ser planejadas e avaliadas com a participação das famílias usuárias, das instituições e redes de serviços e dos movimentos populares do território, visando ao aperfeiçoamento do serviço, a partir 
de sua melhor adequação às necessidades locais, e ao fortalecimento do protagonismo das famílias nos espaços de participação democrática e em instâncias de controle social.

A definição de trabalho social com famílias, a partir do PAIF, está proposta da seguinte forma:

\begin{abstract}
Conjunto de procedimentos efetuados a partir de pressupostos éticos, conhecimento teórico-metodológico e técnico-operativo, com a finalidade de contribuir para a convivência, reconhecimento de direitos e possibilidades de intervenção na vida social de um conjunto de pessoas, unidas por laços consanguíneos, afetivos e/ou de solidariedade que se constitui em um espaço privilegiado e insubstituível de proteção e socialização primárias, com o objetivo de proteger seus direitos, apoiá-las no desempenho da sua função de proteção e socialização de seus membros, bem como assegurar o convívio familiar e comunitário, a partir do reconhecimento do papel do Estado na proteção às famílias e aos seus membros mais vulneráveis. Tal objetivo materializa-se a partir do desenvolvimento de ações de caráter "preventivo, protetivo e proativo", reconhecendo as famílias e seus membros como sujeitos de direitos e tendo por foco as potencialidades e vulnerabilidades presentes no seu território de vivência (BRASIL, 2012, v. 2, p. 11).
\end{abstract}

O PAIF tem papel fundamental na compreensão das especificidades dos territórios, ou seja, de suas vulnerabilidades e potencialidades. Neste aspecto, as normativas apontam o diagnóstico territorial como fundamental para uma leitura crítica da situação vivenciada. A escuta qualificada, no atendimento às famílias e aos grupos sociais residentes no local, possibilita a implementação de ações de caráter preventivo, protetivo e proativo. Logo, é a partir da análise crítica dos aspectos da realidade social evidenciados no território que se planeja o trabalho social a ser desenvolvido com as famílias.

A concepção de família, para a PNAS (BRASIL, 2005a, p. 28), tem como referência o PAIF e é apresentada do seguinte modo: "estamos diante de uma família, quando encontramos um conjunto de pessoas que se acham unidas por laços consanguíneos, afetivos e/ou de solidariedade." Esta é uma visão ampliada de família, pois vai além do modelo nuclear.

Na proteção básica, o trabalho com famílias deve considerar novas referências para a compreensão dos diferentes arranjos familiares, superando o reconhecimento de um modelo único baseado na família nuclear e partindo do suposto de que são funções básicas das famílias: prover a proteção e a socialização dos seus membros; constituir-se como referências morais, de vínculos afetivos e sociais; de identidade grupal, além de ser mediadora das relações dos seus membros com outras instituições sociais e com o Estado (BRASIL, 2005a, p. 35). 
No trabalho social com famílias, é fundamental que o profissional esteja atento aos novos arranjos familiares, para que possa compreender as famílias em suas diferenças e especificidades, de modo a superar o modelo baseado na família nuclear.

Oliveira e José Filho (2009) ressaltam que o fato de se abordar a família enquanto núcleo essencial na sociedade não remete a uma retomada de conceitos familiares conservadores, pois houve, realmente, uma transformação em sua configuração, expressa nos mais diversos tipos hoje existentes. Para tanto, significa reconhecer que as possibilidades de proteção, socialização e criação de vínculos são essenciais para os indivíduos.

Nesse sentido, é fundamental a compreensão da família enquanto uma instância na qual os sentimentos de pertencimento e de identidade social são desenvolvidos e valores e práticas sociais e culturais são transmitidos.

Dessa forma, deve-se reconhecer as formações familiares relacionadas ao contexto social e cultural, considerando-se que alguns fatores podem determinar o cumprimento, pelas famílias, de suas funções de proteção e desenvolvimento de seus membros. No entanto, é essencial reconhecer o Estado enquanto responsável pelo provimento de proteção social às famílias que apresentam algum nível de vulnerabilidade, pois, nesse caso, não se pode atribuir às mesmas a total responsabilidade pelo exercício da proteção.

Em relação ao trabalho social com famílias, Toninato, Tavares e Pessini (2010) apontam que é importante considerar que estas vivem em um contexto que pode ser tanto fortalecedor como esfacelador de suas potencialidades e possibilidades, assim, é necessário compreendê-las em seu movimento. Outro fator importante é visualizar a família em sua diversidade e não apenas nas fragilidades, considerando, para tanto, as respostas encontradas, por elas mesmas, no âmbito de suas culturas.

Mioto (2010, p. 165) apresenta um outro olhar em relação à centralidade da família, que constitui uma nova possibilidade de interpretação da demanda, pois, segundo a autora, "as necessidades trazidas por sujeitos singulares não são mais compreendidas como problemas individuais/familiares", mas como demandas, como "expressões de necessidades humanas não satisfeitas", decorrentes da desigualdade social própria do modo de produção capitalista. Dessa forma, é possível desvincular-se da ideia de que as necessidades das famílias são "casos de família". Outra mudança sinalizada pela autora é 
decorrente de uma nova perspectiva teórica que se refere ao redimensionamento exigido em relação à atuação profissional. Entretanto, considera-se que a possibilidade de postular soluções para os problemas expressos pela família só será efetivada, de fato, com a superação do modo de produção capitalista.

Nesse sentido, o trabalho social realizado com as famílias deve abordar elementos que caracterizam o compromisso ético-político, ou seja, a centralização da ação profissional no que diz respeito ao desenvolvimento de habilidades e à aquisição de acesso a serviços públicos, como direitos do núcleo familiar. Desse modo, não se potencializa a dimensão política que permeia a política de assistência social.

O trabalho social com famílias, conforme Teixeira (2010b), deve ter como objetivo a autonomia e o protagonismo das mesmas, compreendidos na perspectiva de participação social, de forma coletiva. Neste sentido, a autora propõe a superação da visão liberal de autonomia, ou seja, do "ensinar a pescar", sem que seja garantido, enquanto direito, o acesso a condições materiais e subjetivas para tal. Dessa forma, aponta como fundamental a superação da dimensão individualista do conceito de autonomia e o articula com a noção de cidadania, que pressupõe acesso a direitos e à participação ativa na sociedade.

Dessa forma, deve-se ter cautela para que o trabalho social não perca sua dimensão coletiva. Para Teixeira (2010b), o trabalho socioeducativo deve orientar a discussão para questões internas das famílias, com a finalidade de gerar habilidades para o cuidado doméstico e reforçar as responsabilidades familiares, a partir de novos conhecimentos adquiridos e da discussão de seu cotidiano. Para a autora, essas práticas são herdeiras da educação disciplinadora e normatizadora da família, que assumiram versões modernas que escamoteiam a aquisição de novos conhecimentos, atitudes e posturas e do poder de decisão.

Oliveira e José Filho (2009), em relação ao trabalho com famílias, apontam que este deve ser realizado de maneira sistemática, fugindo do pragmatismo ou da abordagem aleatória, pois é de suma importância o desenvolvimento de um vínculo com as famílias atendidas pelo Serviço Social, a fim de se obter um avanço na proposta profissional.

De modo geral, o trabalho realizado com famílias beneficiárias do PBF deve buscar a proteção das mesmas por meio da facilitação do acesso aos direitos sociais e às políticas públicas que viabilizam esses direitos. 
A noção de autonomia como a capacidade de cada sujeito dar conta de sua vida, dos cuidados necessários para que ele caminhe sem a necessidade de benefícios sociais, de aconselhamento e acompanhamentos pode induzi-lo a buscar saídas nele mesmo, em suas capacidades, potencialidades, inclusive do reforço de suas responsabilidades familiares e individuais, e não na luta pelo benefício como um direito, inclusive, universal, como dever do Estado de prover certo padrão digno de vida a todo cidadão, cujas condições são reflexos das desigualdades que afetam as relações familiares (TEIXEIRA, 2010b, p. 13).

A autora refere-se à luta coletiva dos indivíduos em busca de benefícios como direito universal, ou seja, como dever do Estado, que deve garantir um padrão básico para que as famílias possam suprir suas necessidades sociais essenciais para a produção e reprodução social, no contexto do modo de produção capitalista.

Mioto (2004), em relação ao trabalho do assistente social, aponta que um dos desafios do exercício profissional com famílias é que este ainda se movimenta com base em processos pautados em padrões de normatividade e estabilidade. Segundo a autora, o trabalho permanece na perspectiva da funcionalidade e relacionado aos processos de integração e controle social, o que tira o foco da discussão que coloca a família no contexto de uma sociedade desigual, excludente, fruto da conjuntura atual.

Para a autora, o fortalecimento de possibilidades de proteção social, no âmbito da própria família, não restringe as responsabilidades públicas de proteção para com os indivíduos e a sociedade. Assim, trabalhar com famílias é trabalhar com uma rede de vínculos, ou seja, com a comunidade e suas relações sociais, em um contexto sociocultural radicado em um território.

Em relação à abordagem territorial a ser implementada pelos CRASs, no trabalho social com famílias, Andrade (2012) afirma que esta deve se desenvolver, de forma democrática e participativa, com os sujeitos que vivem em determinado território, de modo que se possa produzir, junto com eles, as transformações necessárias. Isso equivale a dizer que a participação crítica dessas famílias constitui uma dimensão estratégica no processo de politização das relações sociais, de modo a romper com a condição histórica de subalternização para o fortalecimento de uma organização coletiva.

Desse modo, com base no conceito de território e em perspectivas e orientações sobre a assistência a famílias beneficiárias do PBF, é necessário que se leve em consideração, no âmbito do trabalho no CRAS, a construção do processo de 
direcionamento e os objetivos do trabalho social, para que o mesmo seja construído de acordo com a realidade da localidade em questão, a partir das necessidades das famílias que ali vivem, com vistas a uma construção coletiva e participativa.

O processo de acompanhamento da família beneficiária deve estar de acordo com os objetivos apresentados pelo programa e com a definição de território, além de envolver vários fatores, entre eles, a postura profissional, que inclui a compreensão desse acompanhamento, assim como, da família em relação ao processo.

O primeiro passo a ser dado pelo profissional do CRAS é o conhecimento do território: as relações sociais existentes, a história, a cultura, a rede de serviços, os atores envolvidos e o perfil dos beneficiários do PBF, ou seja, saber quem são as famílias e como está constituída a comunidade que vive no território.

Assim, é necessário conhecer também as vulnerabilidades que afetam essas famílias no território em que vivem: as múltiplas expressões da questão social; e os processos que causam exclusão de acesso a direitos sociais e pessoais. Com base nesses dados, pode-se construir estratégias de proteção social para essas famílias.

Nesse sentido, não se deve desconsiderar o caráter protetivo da política de assistência social, cujo foco é o acesso a direitos.

\footnotetext{
Pensar a família no campo da proteção social implica reconhecer que a família na sua dimensão simbólica, na sua multiplicidade, na sua organização é importante à medida que subsidia a compreensão sobre o lugar que lhe é atribuído na configuração da proteção social de uma sociedade, em determinado momento histórico (MIOTO, 2010, p. 169).
}

Em relação ao caráter protetivo da política de assistência social, Mioto (2010) faz algumas críticas, pois considera que há uma regressão da participação do Estado Social na provisão do bem estar das famílias. Segundo a autora, o Estado tem desviado a rota da garantia de direitos sociais através da universalização das políticas públicas, ao focalizar apenas os segmentos mais pauperizados da população, por meio do fortalecimento do mercado, enquanto instância de provisão de bem estar, assim como, da organização da sociedade civil como provedora.

Um fator relevante a ser observado, nesse processo de acompanhamento de famílias beneficiárias do PBF, é o fato da referência familiar estar vinculada a apenas um único 
membro, na maioria das situações, à figura da mãe, que acaba assumindo, exclusivamente, a responsabilidade pelos encaminhamentos repassados a outros membros familiares.

Esse fato deve ser considerado, pois o trabalho social com famílias deve incluir atendimento e encaminhamentos a todos os seus membros, para que as responsabilidades sejam assumidas em conjunto, com o consentimento de todos os membros, e a matricialidade sociofamiliar venha, de fato, a acontecer no trabalho social.

Em relação à matricialidade sociofamiliar, Teixeira (2010b) ressalta que, embora a PNAS e o SUAS adotem esse princípio, não superaram a tendência familista da política social brasileira, pois, se, por um lado, o termo significa que a família é a matriz para a concepção e implementação de benefícios, programas e projetos que podem, em hipótese, romper a fragmentação do atendimento, por outro, toma a família como instância primeira e núcleo básico de proteção a seus membros, devendo ser apoiada para que possa exercer sua própria proteção social. Neste sentido, permanece a responsabilização da família, em especial, das mulheres, pela reprodução social e pelos cuidados familiares.

Nesse sentido, segundo Oliveira e José Filho (2009, p. 62):

\begin{abstract}
Auferir para as famílias a divisão de responsabilidades sem dar às mesmas as mínimas condições de suportar o fardo de ser corresponsável por sua subsistência é mais uma transferência de responsabilidades do que uma divisão, pois quando há algo para se dividir, ambos ficam com certa parte. No que diz respeito à família como centralidade nas políticas sociais, o que podemos verificar é que a família ficou com a parte pior: a de sobreviver sem os mínimos meios para atingi-la.
\end{abstract}

No momento em que o acompanhamento se concentra apenas na figura da mãe ou do responsável familiar, a perspectiva da matricialidade sociofamiliar não é respeitada, pois não se consegue construir uma relação com os outros membros familiares, para que se possa conhecer potencialidades, dificuldades, histórias de vida e relações sociais já estabelecidas dentro da família e com a comunidade.

Além disso, observa-se que a mãe ou responsável familiar acaba sendo a referência na escola, na UBS, no CRAS e em outros serviços. Dessa forma, responsabiliza-se uma única pessoa, não favorecendo uma rede de proteção de políticas públicas em torno da família.

A PNAS assinala que, no trabalho social com famílias:

O grupo familiar pode ou não se mostrar capaz de desempenhar suas funções básicas. $\mathrm{O}$ importante é notar que esta capacidade resultada não de uma forma 
ideal e sim de sua relação com a sociedade, sua organização interna, seu universo de valores, entre outros fatores, enfim, do estatuto mesmo da família como grupo cidadão. Em consequência, qualquer forma de atenção e, ou, de intervenção no grupo familiar precisa levar em conta sua singularidade, sua vulnerabilidade no contexto social, além de seus recursos simbólicos e afetivos, bem como sua disponibilidade para se transformar e dar conta de suas atribuições (BRASIL, 2005a, p. 35).

Dessa forma, vale ressaltar a necessidade do trabalho em rede, que deve ser motivado pelos profissionais que atuam no CRAS, no sentido de fortalecer o território, para que, juntos, possam tomar conhecimento da realidade vivenciada pelas famílias, de suas potencialidades, vulnerabilidades e dos riscos sociais existentes. É necessário que a equipe trace objetivos comuns e trabalhe de forma coletiva, pois as vulnerabilidades abarcam questões de educação, saúde, habitação, trabalho, e, portanto, necessitam da articulação e do envolvimento de todas as políticas.

Essa necessidade de articulação entre as políticas pode ser verificada quando o descumprimento das condicionalidades acontece. A mãe ou responsável familiar pelo CadÚnico é chamada ao serviço CRAS para prestar informações sobre o que acontece com o filho, ou seja, para apresentar o motivo de o filho ter faltado à escola ou não ter feito a vacinação na unidade de saúde. A criança ou adolescente, muitas vezes, não é ouvida/o pelo profissional, assim, a mãe ou responsável familiar acaba sendo o elo entre a escola e o CRAS, entre a criança ou adolescente e o CRAS. Este processo dificulta verificação do que, realmente, se passa na família, para que se possa pensar estratégias mais efetivas para os encaminhamentos, o que também necessita da aproximação das políticas envolvidas.

Castilho (2012), em uma pesquisa que incluiu entrevistas com técnicos, aponta que, conforme depoimentos dos mesmos, as estratégias de operacionalização do trabalho social com famílias, nos CRASs, são organizadas a partir da mulher/mãe, pois é ela quem acessa o equipamento, passando a ter titularidade no cadastro e responsabilidade na participação das ações e no cumprimento das condicionalidades previstas para atingir os objetivos do PBF, o que confirma a sustentabilidade dos papéis e funções da mulher/mãe da família nuclear burguesa.

Dessa forma, é notável a necessidade de se criar uma relação de acompanhamento familiar para além da figura da mãe ou responsável familiar, pois é de suma importância 
envolver os outros integrantes da família, bem como, a comunidade pertencente ao território.

Nesse sentido, o trabalho articulado entre as políticas viabiliza a construção de uma intervenção qualificada no núcleo familiar, a fim de que as situações que geraram o descumprimento de condicionalidades sejam identificadas e encaminhamentos e intervenções sejam implementados para a superação das vulnerabilidades, pois só desse modo as condicionalidades cumprirão seu papel como garantidoras do acesso a direitos como saúde e educação.

Ao serem beneficiárias pelo $\mathrm{PBF}$, as famílias se comprometem a cumprir as contrapartidas do programa, nas áreas de saúde e educação. De acordo com o MDS, as condicionalidades buscam contribuir para: a redução da evasão escolar, a melhoria do rendimento escolar, a adesão a consultas de pré-natal e a elevação do nível de vacinação de crianças nas populações mais pobres.

As famílias em situação de descumprimento de condicionalidades, como já citado acima, constituem o público prioritário do trabalho de intervenção profissional do PAIF. Dessa forma, considera-se o acesso à transferência de renda enquanto direito do cidadão e as condicionalidades, como reforço ao acesso a políticas de saúde e à educação. Assim, é necessário um trabalho articulado entre os três níveis de gestão da política, a fim de que as condicionalidades não venham a fragilizar, ainda mais, o núcleo familiar, ocasionando bloqueio ou cancelamento do benefício.

Vale considerar que as famílias que descumprem as condicionalidades, ou seja, que não garantem a frequência escolar de seus membros, bem como, não fazem o acompanhamento dos mesmos na unidade de saúde, passam por sanções que vão desde uma advertência até o cancelamento do benefício. Nesse contexto, pelo não cumprimento das contrapartidas, a família pode ser penalizada com o rompimento do acesso à transferência de renda, o que fragiliza, ainda mais, sua situação.

De acordo com as orientações do MDS, o não cumprimento das condicionalidades deve servir de alerta para a identificação das famílias em situação de maior risco social, ou seja, que necessitam de acompanhamento familiar mais próximo e integrado. Neste sentido, esse acompanhamento também deve contribuir para um redirecionamento de 
políticas públicas, de modo a orientar as ações com vistas à redução da vulnerabilidade e à ampliação de oportunidades e possibilidades de inclusão social para tais famílias.

A imposição de condicionalidades, nos programas de transferência de renda, tem gerado polêmicas entre os que defendem um sistema de proteção social não mercadorizável e de acesso universal. De acordo com Soares e Sátyro (2010), há autores que veem o PBF como um Programa de incentivo ao capital humano das famílias mais pobres, com ênfase no caráter condicionado. Existe outra vertente, para a qual, o Programa é, antes de tudo, proteção social. Quando se coloca contrapartidas excessivas, a função de proteção social se enfraquece, pois, provavelmente, as famílias mais vulneráveis serão as que não conseguirão cumprir as exigências mais rigorosas (CARLOTO, 2012)

Vale considerar que o trabalho de identificação de situações que ocasionam o descumprimento de condicionalidades, de forma preventiva, permite que não haja reincidências no descumprimento, pois direciona a ação de modo a atender as reais necessidades demandadas pelas famílias que vivenciam essa situação.

No âmbito do trabalho social com famílias beneficiárias do PBF, não se pode deixar de considerar a interdisciplinaridade das ações desenvolvidas no CRAS, ou seja, o trabalho articulado entre o assistente social e o psicólogo, o que fortalece e proporciona uma intervenção mais qualificada na realidade.

A psicologia tem fortalecido o trabalho social à medida que constrói, em conjunto com o serviço social, uma leitura das situações vivenciadas pelas famílias a partir da realidade social, proporcionando, assim, um trabalho direcionado para uma prática de fortalecimento comunitário e familiar, pois atua na subjetividade, nas histórias de vida e na reconstrução de significados.

Teixeira (2010a) aponta um desafio no trabalho interdisciplinar, pois considera necessário trabalhar com essas famílias de forma dialética, articulada, em relação a questões internas e externas, numa perspectiva de totalidade, ou seja, sem supervalorizar as questões subjetivas ou internas às famílias, porque o objetivo deve ser sempre o alargamento da percepção das situações pessoais e sociais e a luta pela garantia dos direitos.

O trabalho social articulado, que envolve outras áreas do saber, viabiliza uma leitura crítica da realidade, o que pode acarretar a busca da perspectiva de totalidade, ou seja, a 
compreensão efetiva das famílias que vivem em determinado território, de modo a intervir de forma propositiva no contexto social, respeitando necessidades, potencialidades e histórias de vida.

Nesse sentido, é importante compreender o território para além de suas dimensões geográficas e visualizar não só o que está aparente, ou seja, as relações sociais, as histórias de vida e a cultura envolvidas nesse processo.

Além disso, é fundamental a articulação da rede socioassistencial da área de abrangência territorial do CRAS com o PAIF, objetivando o desenvolvimento do trabalho social com as famílias dos usuários dos serviços. Esta articulação, ao mesmo tempo que possibilita a identificação das necessidades e potencialidades em uma perspectiva familiar, rompe com o atendimento segmentado e descontextualizado das situações de vulnerabilidade sociais vivenciadas pelas famílias.

Castilho (2012) aponta que o trabalho social previsto pelo PAIF deve contribuir para a proteção integral de toda a família e para a materialização da matricialidade sociofamiliar no âmbito do SUAS. Trabalho social que se apresenta, na tipificação dos serviços, como essencial para a proteção integral à família.

Para Andrade (2012), o que está em questão é o estímulo ao fortalecimento da participação e da ação política pela população usuária, desde a realização de uma leitura crítica da realidade vivida até a luta pelos direitos socioassistenciais a serem assegurados, de forma territorializada, pelo Estado, ou seja, o direito da população de acessar e usufruir da totalidade dos bens públicos produzidos pela cidade.

\footnotetext{
Em relação aos profissionais da equipe interdisciplinar, exige-se postura crítica que vise o protagonismo dos usuários, dentro do quadro das lutas por seus direitos de cidadania concomitante ao de suas relações familiares; portanto, para atender suas necessidades, além de abertura para a realidade social para além do grupo familiar e realidade do território, tanto na análise da realidade e dos problemas como na intervenção para resolvê-los (TEIXEIRA, 2010b, p. 21).
}

Sob esse enfoque, os profissionais devem trabalhar para construir, com as famílias beneficiárias, um trabalho coletivo, no sentido de torná-las pertencentes ao território em que vivem, criando uma identidade no espaço em questão, de modo que os objetivos sejam comuns e que todos os membros familiares, a comunidade e a rede de serviços sejam considerados pertencentes ao processo. 
Andrade (2012) ressalta ainda que:

\begin{abstract}
É nessa arena pública, permeada de conflitos, que se situam os desafios a serem compreendidos, explicitados e enfrentados pelos trabalhadores sociais, com especial ênfase aos Assistentes Sociais, no sentido de nutrir cada iniciativa e movimento realizado pela população usuária, estimulando a apropriação gradativa e contínua do espaço socialmente produzido. A direção social anunciada certamente será resultado do compromisso ético-político, sustentado por procedimentos técnico-operativos definidos a partir de um consistente referencial teórico-metodológico crítico. Tais pressupostos colocam-se enquanto exigência profissional a ser assegurada, de modo que o exercício profissional, em seu cotidiano, possa, efetivamente, produzir ações que contribuam com o fortalecimento e a qualificação política da participação e da organização coletiva da população usuária na luta por seus direitos (ANDRADE, 2012, p. 158).
\end{abstract}

Nesse contexto, é necessário, como pontua o autor, que a intervenção profissional esteja articulada ao projeto ético-político que direciona as ações de forma crítica e propositiva.

Segundo Toninato, Tavares e Pessini (2010), para a compreensão da situação e da realidade da família, devem ser considerados os referenciais sociais e culturais da sociedade atual, pois cada família tem sua versão da história de vida à qual dá um significado particular. Neste sentido, trabalhar com essas famílias requer: identificação dos pontos de vulnerabilidade; espaço de escuta qualificada; e utilização dos recursos disponíveis.

O trabalho coletivo faz com que as situações identificadas não sejam apenas particularizadas e enfrentadas de forma isolada, mas coletivamente, pois só assim se pode alcançar a participação de todos e, consequentemente, a efetivação de mudanças capazes de afetar todo o território.

Nesse sentido, o trabalho socioeducativo pode ser uma importante ferramenta quando executado com traços emancipatórios. Para Teixeira (2010b, p. 19), o trabalho social com famílias não deve se restringir à responsabilização das mesmas, tampouco a ensiná-las a gerir seus conflitos, recursos e vida, mas "deve-se evitar essa dimensão disciplinadora e levar as famílias a refletirem sobre sua realidade, conhecer serviços e recursos do território, mobilizar-se e incluir-se em processos organizativos, coletivos, na busca de garantia dos seus direitos."

\title{
Considerações finais
}


Primeiramente, é necessário que se tenha a compreensão de que é fundamental reconhecer o território enquanto espaço vivido de grupos e indivíduos que se relacionam e possuem histórias de vida e culturas já estabelecidas. O território é onde se inicia a compreensão de toda a possibilidade de trabalho que pode ser desenvolvido por um serviço ou política em um determinado espaço, que não pode ser considerado somente enquanto espaço geográfico.

Dessa forma, compreender a territorialização é um avanço trazido pela PNAS, pois possibilita um estudo das especificidades encontradas nos diferentes espaços territoriais de uma determinada região. Essa perspectiva facilita a criação de ações voltadas para o atendimento das demandas trazidas pelas famílias que vivem em determinado espaço.

Nesse sentido, o CRAS, que tem o território enquanto eixo estruturante da proteção social básica, deve ser motivador do conhecimento das relações que o envolvem. Assim, é necessário conhecer as famílias em suas limitações, potencialidades e vulnerabilidades, não as responsabilizando pelas dificuldades encontradas no processo de acompanhamento e atendimento das demandas trazidas ao serviço. Desse modo, é preciso compreender as famílias no contexto de desigualdade social gerado pelo modo de produção capitalista, de forma a não individualizar seu enfretamento.

Portanto, é fundamental adotar um referencial teórico pautado na defesa de direitos, com vistas à autonomia e à cidadania das famílias beneficiárias, estimulando a participação das mesmas no processo de planejamento, execução e avaliação das atividades em que estão envolvidas, de forma a proporcionar o protagonismo e combater práticas modeladoras e prescritivas.

Nesse sentido, esse trabalho é essencial para a compreensão da realidade local e para o atendimento efetivo das demandas trazidas pelas famílias. Desse modo, o assistente social deve desenvolver suas atribuições não de forma burocrática e terminal de políticas sociais, mas de maneira comprometida com os princípios do projeto ético-político da profissão.

O trabalho social direcionado ao atendimento/acompanhamento dessas famílias, no âmbito do território, deve ser pautado no objetivo de alcançar um processo de superação de vulnerabilidades e de acesso a direitos, de modo a garantir, de fato, a vivência das seguranças afiançadas pela PNAS, tais como: acolhida, renda, convivência familiar e 
comunitária, desenvolvimento da autonomia e sobrevivência a riscos circunstanciais. Esse trabalho contribui para a materialização do direito das famílias à proteção do Estado.

O trabalho articulado entre as políticas públicas e o território habitado viabiliza um sistema de proteção social para além da assistência social, com a participação de outras políticas, pois a compreensão das famílias que vivem em determinado espaço possibilita o enfretamento efetivo das vulnerabilidades.

Dessa forma, para se alcançar uma efetiva proteção às famílias, o trabalho social com as mesmas requer um avanço na potencialização da rede de serviços públicos e privados e uma articulação intersetorial entre eles.

O trabalho social deve ser direcionado com base na compreensão dos sujeitos e das famílias enquanto seres de direito, pela identificação e encaminhando de demandas, o que possibilita a visualização de possíveis soluções e intervenções, com o intuito de se superar a responsabilização dos indivíduos por suas vulnerabilidades, mediante a disponibilização de serviços e políticas articulados, com o objetivo de viabilizar a proteção social.

A articulação de políticas, no âmbito do território de abrangência do CRAS, pode proporcionar acompanhamentos e encaminhamentos efetivos às famílias beneficiárias do PBF, no sentido de facilitar o acesso a direitos e melhorar a qualidade de vida das mesmas e da comunidade em geral.

O trabalho socioeducativo realizado com as famílias, sob a perspectiva do território enquanto espaço habitado e vivido, deve disponibilizar informações e proporcionar reflexões, de forma crítica, sobre a realidade e sobre o contexto social, para que haja mobilização e organização em prol da garantia de direitos.

\section{Referências}

ANDRADE, I. Território e assistência social: uma análise do serviço social a partir da produção social do espaço. 2012. Tese (Doutorado em Serviço Social) - Pontifícia Católica do Rio Grande do Sul, Porto Alegre, 2012.

BRASIL. Decreto no 5.209 de 17 de setembro de 2004. Regulamenta a Lei no 10.836, de 9 de janeiro de 2004, que cria o Programa Bolsa Família, e dá outras providências. Disponível em: <http://www.planalto.gov.br/ccivil_03/_ato20042006/2004/decreto/d5209.htm>. Acesso em: 16 fev. 2013. 
. Ministério de Desenvolvimento Social e Combate à Fome. Centro de Referência e Assistência Social - CRAS. Orientações Técnicas Centro de Referência de Assistência Social - CRAS. Brasília, 2009a.

. Ministério de Desenvolvimento Social e Combate à Fome. CapacitaSuas.

Desafios da Gestão do SUAS nos Municípios e Estados. Brasília, v.02, 2008.

. Ministério de Desenvolvimento Social e Combate à Fome. Norma Operacional Básica - NOB/SUAS. Brasília, 2005a.

Ministério de Desenvolvimento Social e Combate à Fome. Orientações para o acompanhamento das famílias beneficiárias do Programa Bolsa Família no âmbito do Sistema Único de Assistência Social (SUAS): versão preliminar. Brasília, 2006a. Disponível em: <http://www.redesabara.org.br/downloads/2009/ famlia_orientao\%20acompanhamento_mds.pdf>. Acesso em: 16 fev. 2013.

Ministério de Desenvolvimento Social e Combate à Fome. Orientações técnicas sobre o PAIF. Brasília: MDS, 2012. 2 v.

. Ministério de Desenvolvimento Social e Combate à Fome. SUAS: proteção social básica: orientações técnicas. Brasília: MDS, 2009b.

- Ministério do Desenvolvimento Social e Combate à Fome. Política Nacional de Assistência Social. Brasília: MDS, 2005b.

Secretaria Nacional de Renda de Cidadania. Guia do gestor. Brasília: MDS, 2006b.

CARLOTO, C. M. Condicionalidades nos programas de transferência de renda e autonomia das mulheres. Sociedade em Debate, Uberlândia, v. 8, n. 2, 2012.

CASTILHO, C. F. V. A operacionalização do trabalho social com familias nos CRAS do município de Maringá-PR. 2012. 165 f. Dissertação (Mestrado em Serviço Social e Política Social) - Universidade Estadual de Londrina, Londrina, 2012.

KOGA, D. Medidas de cidades: entre territórios de vida e territórios vividos. São Paulo: Cortez, 2003.

LOUGON, A. N.; CRUZ, M. F. S.; SANTOS, P. A. O território e a política de assistência social. In: JORNADA INTERNACIONAL DE POLÍTICAS PÚBLICAS, 3., 2007, São Luiz. Anais... São Luiz, 2007.

MIOTO, C. R. T. Trabalho com famílias: um desafio para os assistentes sociais. Revista Virtual Textos \& Contextos, Porto Alegre, n. 3, dez. 2004. Disponível em:

$<$ http://revistaseletronicas. pucrs.br/ojs/index.php/fass/article/view/979 $\geq$. Acesso em: 17 ago. 2013

MIOTO, R. C. Família, trabalho com famílias e serviço social. Serviço Social em Revista, Londrina, v. 12, n. 2. p. 163-176, jan./jun. 2010. 
OLIVEIRA, N. H. D.; JOSÉ FILHO, M. O trabalho social com famílias: repercussões, possibilidade e desafios. Serviço Social e Realidade, Franca, v. 18, n. 2, p. 55-80, 2009.

SANTOS, M. O espaço dividido: os dois circuitos da economia urbana dos países subdesenvolvidos. 2. ed. São Paulo: EDUSP, 2000.

SILVA, D. M. Limites e possibilidades do programa bolsa família no município de Marilândia do Sul - Pr. 2007. Trabalho de Conclusão de Curso (Graduação em Serviço Social) - Faculdade Estadual de Ciências Econômicas de Apucarana, Apucarana, 2007.

SOARES, Sergei; SÁTYRO, Natália. O Programa Bolsa Família: desenho institucional e possibilidades futuras. In: CASTRO, Jorge A.; MODESTO, Lúcia (org.). Bolsa Família 20032010: avanços e desafios. Brasília: IPEA, 2010. 2 v. p. 25-56.

SUPLICY, Eduardo Matarazzo. Renda de cidadania: a saída é pela porta. 3. ed. Aumentada, São Paulo: Cortez / Fundação Perseu Abramo, 2004.

TEIXEIRA, S. M. Trabalho interdisciplinar no CRAS: um novo enfoque e trato a pobreza. Textos\& Contextos, Porto Alegre, v. 9, n. 2, p. 286-297, ago./dez. 2010a. Disponível em: $<$ http://revistaseletronicas.pucrs.br/ojs/index.php/fass/article/viewFile/7032/5781>. Acesso em: 26 ago. 2013.

Trabalho social com famílias na política de assistência social: elementos para sua reconstrução em bases críticas. Serviço Social em Revista, Londrina, v. 13, n. 1, p. 4-23, jul./dez. 2010b.

TONINATO, J. S.; TAVARES, T.; PESSINI, M. A. As contribuições do Centro de Referência de Assistência Social (CRAS) às famílias em vulnerabilidade/risco social. AkrópolisUmuarana, Umuarama, v. 18, n. 4, p. 247-261, out./dez. 2010.

WEISSHEIMER, M. A. Bolsa família: avanços limites e possibilidades do programa que está transformando a vida de milhões de famílias no Brasil. São Paulo: Fundação Perseu Abramo, 2006. 